\title{
HOMEOPATHY IN THE TREATMENT OF RECURRENT URINARY TRACT INFECTION A CASE REPORT
}

\author{
DEEPEN BARUAH ${ }^{1}$, ABHIJIT DUTTA ${ }^{2 *}$ \\ ${ }^{1}$ Department of Practice of Medicine, National Institute of Homoeopathy, Kolkata, West Bengal, India. ${ }^{2}$ Department of Organon of \\ Medicine, National Institute of Homoeopathy, Kolkata, West Bengal, India. Email: drabhijitdutta1@gmail.com
}

Received: 24 Dcember 2019, Revised and Accepted: 07 January 2020

\section{ABSTRACT}

Objectives: Urinary tract infection (UTI) is a leading cause of morbidity and health-care expenditures in persons of all ages. Recurrent UTI accounts a substantial portion due to its ambiguity of treatment and response. Only using palliative treatment during episodes is not enough to assure the complete resolution of the disease process. Apart from conventional medication, an alternative therapy is warranted for a better and gentle treatment regimen.

Methods: This is the case of a 35-year-old female presented with the complaint of recurrent UTI for last 5 months along with some other complaints. After a thorough evaluation, we treated the case with homeopathic medicine, Lycopodium clavatum for a considerable period. The clinical assessment in different visits was done to note any improvement along with the pre-post pathological report. After complete resolution of symptoms, no further recurrence was noted in the next 6 months of follow-up.

Results: A marked improvement in the clinical, as well as the pathological aspect, was observed.

Conclusion: Although depending only on the observation of this case report efficacy cannot be established, it inevitably draws attention toward effective management of such recurrent UTI cases with homeopathic medication.

Keywords: Urinary tract infection, Lycopodium clavatum, Homeopathy.

\section{INTRODUCTION}

Urinary tract infection (UTI) is the infection of kidney, ureter, bladder, and urethra. It is one of the commonly encountered problems in the clinical practice of the present scenario. It has been estimated that symptomatic UTI results in as many as 7 million visits to outpatient clinics, 1 million visits to emergency departments, and 100,000 hospitalizations annually [1] Around $40 \%$ of women experience at least one episode of UTI in their lifetime [2]. Among them, roughly 27\% recur and sometimes present as chronic or resistant to treatment variety [3]. UTI causes considerable morbidity and accounts for $10 \%$ of primary care consultations [4]. The usual uropathogens include Escherichia coli, Staphylococcus saprophyticus, Klebsiella pneumonia, and Proteus mirabilis [5]. Pathologically, it is associated with the multiplication of organisms in the urinary tract and is defined by the presence of more than $10^{5} \mathrm{CFU} / \mathrm{ml}$ in a midstream, early morning sample of urine. However, significant bacteria may lack in some cases of true UTI, even in symptomatic patients [6].

At present, the treatment of UTI has become one of the major concerns, maybe due to so many resistant or underreported cases. According to some studies, constitutional homeopathic treatment can improve symptoms of UTI $[7,8]$. We present a case of recurrent, uncomplicated UTI, which was treated with conventional medications but responded poorly. After a thorough case taking and clinical evaluation, we prescribed Lycopodium clavatum. All the symptoms were ameliorated within 4 months of treatment, and we found no recurrence in the next 6 consecutive months of follow-up. The condition of the patient and improvement is documented clinically as well as pathologically.

\section{PATIENT PROFILE}

A 35-year-old female presented with the complaints of frequent micturition (daytime frequency $>15$ and nighttime frequency $>4$ ), unable to hold urine during urge, involuntary dribbling while coughing or sneezing, burning, and pain in lower abdomen after urination. The complaint is persisting for 5 months with increasing and decreasing intensity which responded poorly with conventional medications.

Her other complaints were, bilateral pain in soles for the past 2 months during walking, cramping pain in calf muscles for the past 3-4 years, bilateral knee pain which is aggravated by rising from seat; hot vertex; itching of extremities; increased by heat; and pain in the right wrist joint.

Physical generals

She is chilly in thermal relation and tendency to catch cold easily. Her appetite is less, but every kind of food intake causes flatulence, acidity, sour

Table 1: Analysis and evaluation of symptoms

\begin{tabular}{ll}
\hline Mental & Desire for company \\
generals & Forgetful \\
Physical & General modalities: < Cold drinks > warm food and drinks \\
generals & Loss of appetite \\
& Perspiration less \\
& Thermal reaction: Chilly ${ }^{++}$ \\
& Desire: Sweets and warm foods \\
& Frequency of urination day and night \\
& Urgency cannot hold urine during urge \\
& Involuntary urine during coughing and sneezing \\
Particulars & Burning and pain in urethra during urination \\
& Aching pain in the lower abdomen (bladder region) after \\
& urination \\
& Palpitation heart <after eating, during flatulence \\
& Sour eructation after a meal \\
& Pain in bilateral soles during walking \\
& Cramping calves bilateral \\
& Bilateral knee pain < rising from seat \\
& Pain in right wrist joint \\
& Pain in soles during walking \\
&
\end{tabular}




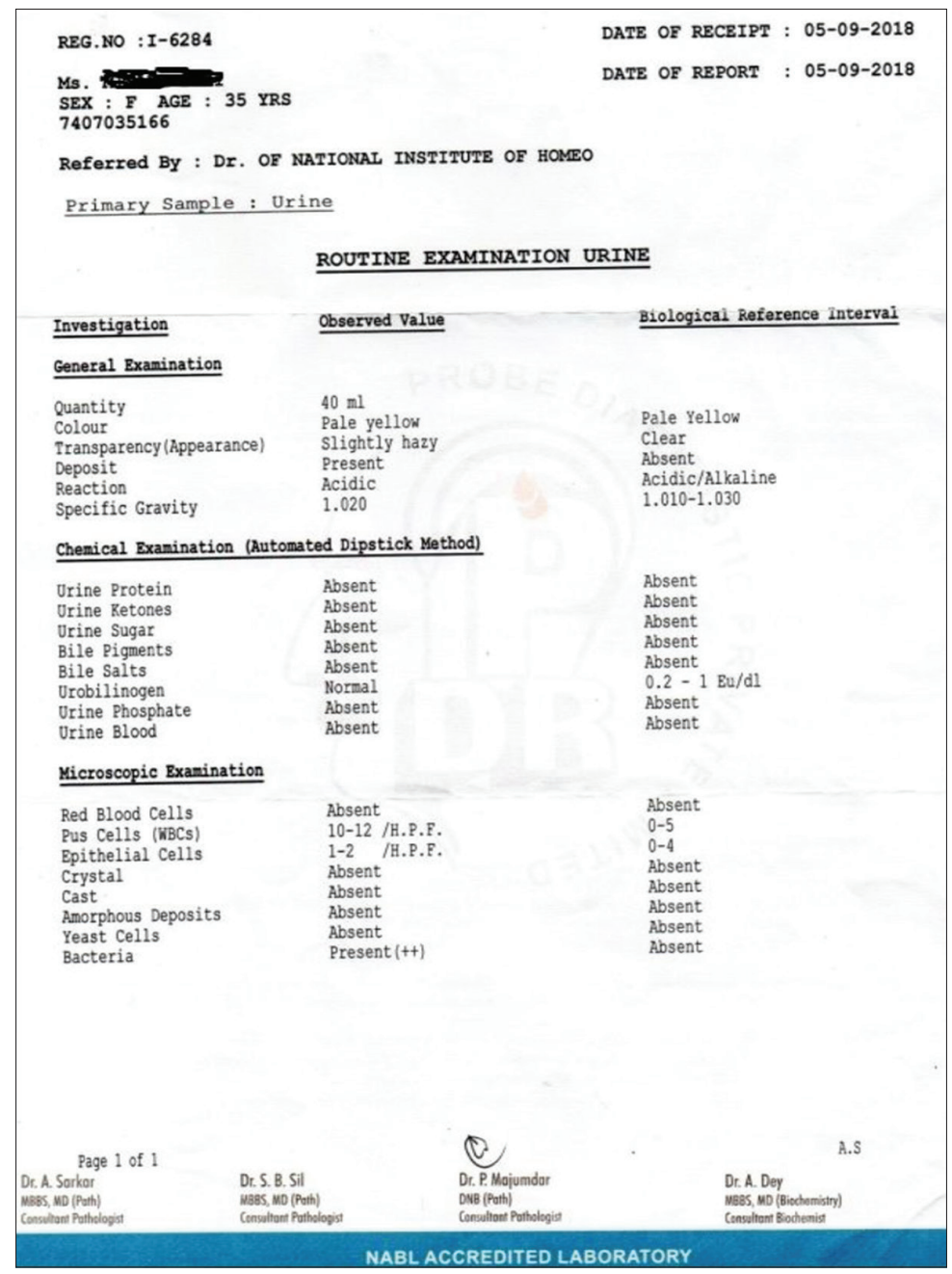

Fig. 1: Routine examination of urine (Before treatment)

Table 2: Repertorization



eructation, and sometimes associated with palpitation. She has a desire for sweets and warm food. Her thirst is for a moderate quantity of cold water which measures around 2-3 L/day. She has no disturbances with sleep and dream. She had her menarche at the age of 12 years. Her menstrual cycle is a regular, moderate amount of flow and lasts for 3-4 days without any associated complaints. The last menstrual period was on August 29, 2018. 


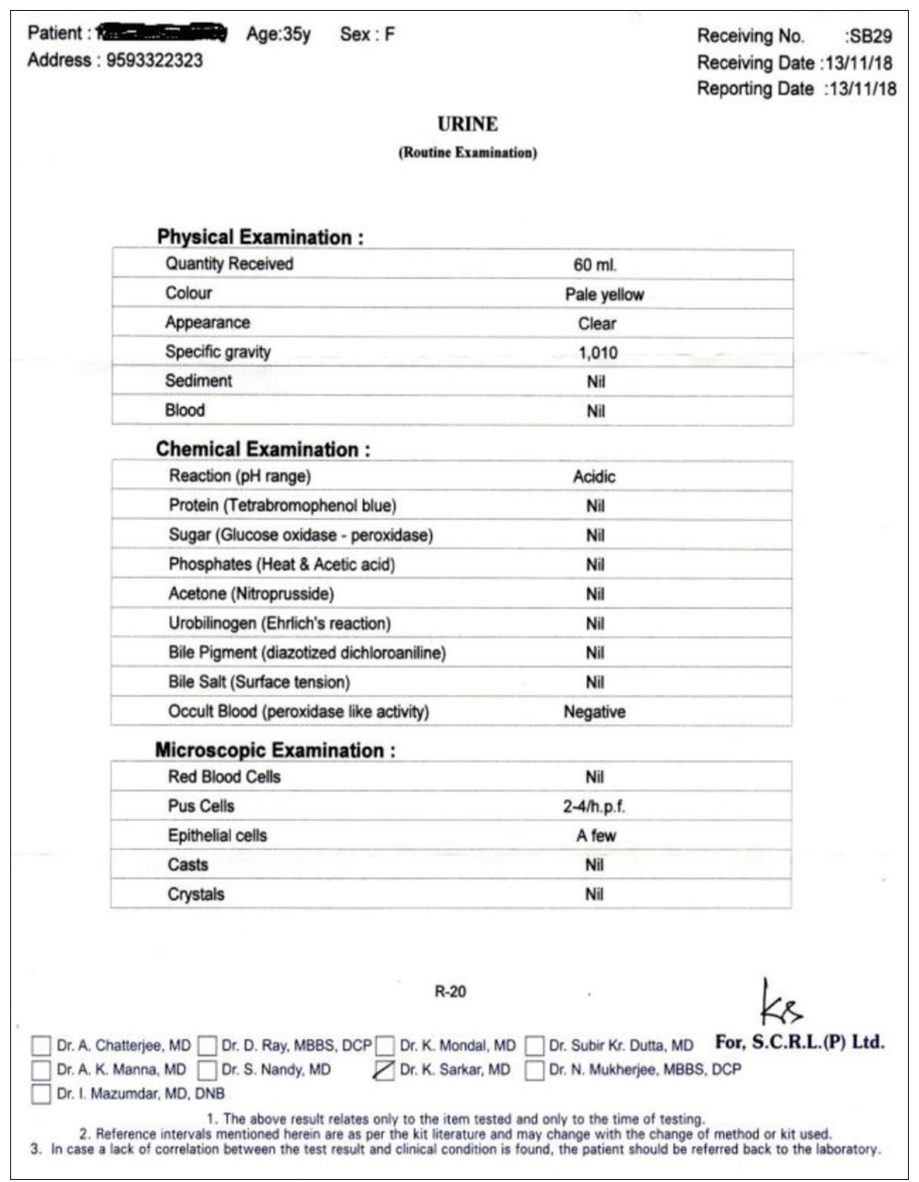

Fig. 2: Routine examination of urine (After treatment)

Table 3: Prescription and follow-up

\begin{tabular}{|c|c|c|c|}
\hline Date of visit & Observation and result & Medicine with doses & Administration of medicine \\
\hline September 6, 2018 & $\begin{array}{l}\text { Urinalysis report (September } 5,2018 \text { ) reveals } \\
\text { pus cell } 10-12 / \text { hpf, epithelial cell } 2-4 / \mathrm{hpf}, \\
\text { bacteria (++) (Fig. 1) }\end{array}$ & $\begin{array}{l}\text { Lycopodium clavatum Q1, } \\
16 \text { doses } \\
\text { Once in a day for } 16 \text { days }\end{array}$ & $\begin{array}{l}\text { One globule no. } 10 \text { of medicine mixed with } \\
60 \mathrm{~mL} \text { aq. Dist. and few drops of alcohol to } \\
\text { make } 16 \text { doses. One dose to be taken every } \\
\text { day at morning in empty stomach after } \\
\text { giving } 10 \text { uniform downward strokes }\end{array}$ \\
\hline September 22, 2018 & $\begin{array}{l}\text { Frequency of micturition reduced }(D=10, N=3-4) \text {, } \\
\text { no sour eructation after eating, knee pain slight } \\
\text { better, pain in bladder after urination reduced, } \\
\text { burning in urethra during urination reduced but } \\
\text { sole and wrist pain are same }\end{array}$ & $\begin{array}{l}\text { Lycopodium clavatum } \mathrm{Q} 2 \text {, } \\
16 \text { doses } \\
\text { Once in a day for } 16 \text { days }\end{array}$ & Same as before \\
\hline October 10, 2018 & $\begin{array}{l}\text { Frequency reduced }(D=7-8, N=2) \text {; knee pain } \\
\text { better only increased after much walking, burning } \\
\text { in urethra, and post-micturition bladder pain } \\
\text { reduced, sole and wrist pain are as before }\end{array}$ & $\begin{array}{l}\text { Lycopodium clavatum } \mathrm{Q} 3 \text {, } \\
\text { Q4 } 16 \text { doses each } \\
\text { Once in a day for } 32 \text { days }\end{array}$ & Same as before \\
\hline November 14, 2018 & $\begin{array}{l}\text { Frequency reduced ( } D=5-6, N=1) \text {, now the patient } \\
\text { can hold urine, no burning in urethra during } \\
\text { urination, sometimes patient feels pain in bladder } \\
\text { region, calf pains occasionally, sole pain reduced. } \\
\text { Knee pain same as before. Rarely, involuntary urine } \\
\text { in drops during coughing } \\
\text { Urinalysis report (November } 13,2018 \text { ) reveals only } \\
\text { pus cells 2-4/hpf and few epithelial cells (Fig. 2) }\end{array}$ & $\begin{array}{l}\text { Lycopodium clavatum } \mathrm{Q} 5 \text {, } \\
\text { Q6 } 16 \text { doses each } \\
\text { Once in a day for } 32 \text { days }\end{array}$ & Same as before \\
\hline December 17, 2018 & $\begin{array}{l}\text { No pain and burning in urethra during urination, } \\
\text { knee pain reduced markedly, no urgency, or } \\
\text { involuntary micturition }\end{array}$ & $\begin{array}{l}\text { Only advice for maintaining } \\
\text { hygiene and to report any } \\
\text { further recurrence }\end{array}$ & \\
\hline $\begin{array}{l}\text { Continued follow-up } \\
\text { up to June } 30,2019\end{array}$ & No further recurrence of symptoms & & \\
\hline
\end{tabular}


Mentally, she is very forgetful of both recent and past memory. She has a desire for the company due to a sense of insecurity while alone.

In a history, she had an injury to the right wrist joint after falling 1 year back. In family, her mother had osteoarthritis of both knee joints.

\section{Personal history}

She is a housewife, belongs to a lower socioeconomic condition, and has two sons and two daughters. She has a good social relationship and no habit of addiction in the past or present. She is sexually active and uses a barrier method during intercourse. Previously, she was also using oral contraceptive pills for years, but now stopped for few months.

On physical examination, no pallor, jaundice, cyanosis, edema, pigmentation, or lymphadenopathy were detected; the temperature was $99.5^{\circ} \mathrm{F}$. Mild tenderness found on palpation of the suprapubic region.

Urinalysis report shows the presence of bacteria $(++)$ and pus cells: 10-12/HPF (Date: September 5, 2018).

\section{Diagnosis}

Based on the history and clinical examination, we diagnosed the case as recurrent UTI (N39.0 is a specific 2018/19 ICD-10-CM code) [9] which was further supported by the urinalysis report.

\section{ANALYSIS OF THE CASE}

We analyzed and evaluated the characteristic mental, physical, and particular symptoms according to the priority (Table 1) for framing the complete picture of the case.

\section{REPERTORIAL ANALYSIS AND PRESCRIPTION}

Considering the above symptomatology, we repertorized the case using Kent's Repertory in RADAR software (Table 2). Most of the symptoms covered by L. clavatum, Nux vomica, and Sulphur. After a thorough evaluation and consulting Materia medica [10], we prescribed L. clavatum in Q1 potency (50 millesimal) on September 6, 2018. We treated the case up to December 17, 2018, with successive potencies of the same medicine. In all visits, we advised the patient for maintaining local hygiene and protected sexual intercourse. After the complete resolution of symptoms, the patient did not report any further recurrence in the next 6 months of follow-up (Table 3).

\section{DISCUSSION AND CONCLUSION}

UTI is a common clinical condition, but the chronic or recurrent variety is not as frequent as the acute one [11]. In the case of chronic or recurrent UTI, it is often found to be challenging to treat partly due to its resistant nature. Diagnosis of recurrent UTI depends on the characteristic of clinical features, history, three positive urinary cultures within the previous 12-month period in symptomatic patients, and the presence of neutrophils in the urine (pyuria) [12]. Due to the diverse nature of symptoms, recurrent UTI hampers the quality of life drastically.

Hence, many medicines are depicted in different homeopathic Materia medicas but which medication will be chosen, ultimately depends on the individuality of the patient in terms of his history and presenting symptoms. Characteristic symptoms obtained from the thorough case history. On the basis of that, there were a couple of suggestive medicines after consultation with repertory. However, the most appropriate one (i.e., L. clavatum) was selected based on the totality of symptoms including different sides of the whole anamnesis of the patient. In the follow-ups, we thoroughly assessed the clinical situation that the patient presented, and according to that, the intervention was given.

Previously, a case series on the prevention of UTIs in patients with neurogenic bladder dysfunction was published [7]. A randomized clinical trial evaluating the efficacy of tuberculinum revealed its positive role on UTI [8]. However, this case report of 5 months duration reflects a very different nature and course. Successful treatment demonstrates better management of such cases with individualized homeopathic treatment. No conclusion regarding the efficacy can be drawn from this case report, but a large scale, well-designed controlled trial is warranted.

\section{CONSENT}

The study was verbally explained to the patient, and written consent was obtained. However, the patient was free to withdraw from the study at any time. For the ethical purpose, if any poor prognosis were suspected, then she would be referred to a regional center as per government norms.

\section{CONFLICTS OF INTEREST}

The authors have no conflicts of interest.

\section{REFERENCES}

1. Schappert SM. Ambulatory care visits to physician offices, hospita outpatient departments, and emergency departments: United States, 1997. Vital Health Stat 13 1999;143:1-4, 1-39.

2. Ikäheimo R, Siitonen A, Heiskanen T, Kärkkäinen U, Kuosmanen P, Lipponen $\mathrm{P}$, et al. Recurrence of urinary tract infection in a primary care setting: Analysis of a 1-year follow-up of 179 women. Clin Infect Dis 1996;22:91-9.

3. Foxman B. Recurring urinary tract infection: Incidence and risk factors. Am J Public Health 1990;80:331-3.

4. Orenstein R, Wong ES. Urinary tract infections in adults. Am Fam Physician 1999;59:1225-34, 1237.

5. Echols RM, Tosiello RL, Haverstock DC, Tice AD. Demographic, clinical, and treatment parameters influencing the outcome of acute cystitis. Clin Infect Dis 1999;29:113-9.

6. Wilson ML, Gaido L. Laboratory diagnosis of urinary tract infections in adult patients. Clin Infect Dis 2004;38:1150-8.

7. Pannek J. Usefulness of classical homoeopathy for the prevention of urinary tract infections in patients with neurogenic bladder dysfunction: A case series. Indian J Res Homoeopathy 2014;8:31-36.

8. Padamprakash B. The Efficacy of Tuberculinum Bovinum in Urinary Tract Infections. In: Proceeding 34 ${ }^{\text {th }}$ LMHI Congress; 1979. p. 331-6.

9. ICD-10-CM Diagnosis Code No. 39. Urinary Tract Infection, Site Not Specified; 2020. Available from: https://www.icd10data.com/ ICD10CM/Codes/N00-N99/N30-N39/N39-/N39.0. [Last accessed on 2019 Dec 21]

10. Clarke JH. Lycopodium clavatum. A Dictionary of Practical Materia Medica. New delhi: B Jain Publishers (P) LTD.; 2010. p. 329-48.

11. Al-Badr A, Al-Shaikh G. Recurrent urinary tract infections management in women: A review. Sultan Qaboos Univ Med J 2013;13:359-67.

12. Gopal M, Northington G, Arya L. Clinical symptoms predictive of recurrent urinary tract infections. Am J Obstet Gynecol 2007;197:74. e1-4. 